\title{
Comparison of Multiple Lapse Time Window Analysis and Qopen to determine intrinsic and scattering attenuation
}

\author{
M. van Laaten ${ }^{\odot}$, T. Eulenfeld and U. Wegler \\ Institute of Geosciences, Friedrich Schiller University Jena, Burgweg 11, 07749 Jena, Germany. E-mail: marcel.vanlaaten@uni-jena.de
}

Accepted 2021 September 21. Received 2021 September 17; in original form 2021 May 4

\begin{abstract}
SUMMAR Y
This study compares the results of Multiple Lapse Time Windows Analysis (MLTWA) and full envelope inversion (Qopen) to determine intrinsic and scattering attenuation of the crust using the region around the central part of the Leipzig-Regensburg fault zone in Germany as an example. We use 18 of the region's strongest earthquakes from 2008 to 2019 with a magnitude between 1.4 and 3.0 in the frequency band range between 3 and $34 \mathrm{~Hz}$. The determined attenuation values of both methods are similar within their error bars. The inverse quality factors of the shear wave are relatively low compared to other regions, with values of $3.2 \times 10^{-4}$ to $8.7 \times 10^{-4}$ for $Q_{i}^{-1}$ and $1.4 \times 10^{-4}$ to $2.8 \times 10^{-4}$ for $Q_{s c}^{-1}$, respectively. As a by-product of Qopen, we also obtain the energy site amplification of the stations used in the inversion as well as source displacement spectra and moment magnitudes of the inverted earthquakes. Several combinations of inversion parameters were tested for MLTWA, with $Q_{i}^{-1}$ and $Q_{s c}^{-1}$ providing the lowest trade-off. Likewise, we investigated the influence of window length on the results of Qopen. We found a dependency of the results on the length, if the windows are shorter than $30 \mathrm{~s}$. For longer time windows, the dependence disappears, and the result becomes independent of window length.
\end{abstract}

Key words: Europe; Inverse theory; Coda waves; Seismic attenuation.

\section{INTRODUCTION}

Seismic attenuation provides valuable information about the structure of the crust and is important to analyse earthquakes. Over time, different methods have been developed to calculate seismic attenuation (e.g. Shearer \& Earle 2004; Saito et al. 2005; Calvet et al. 2013; Mayor et al. 2016; Shito et al. 2020), each with its advantages and disadvantages. Various studies have already drawn a comparison between some of these methods, for example, Bachura \& Fischer (2016), Gaebler et al. (2015) or Eulenfeld \& Wegler (2017). However, a comparison between the two commonly used methods of Multiple Lapse Time Window Analysis (MLTWA) and Separation of intrinsic and scattering Q by envelope inversion (Qopen) with the same data does not yet exist. In this study, we focus on the determination of $S$-wave scattering $Q_{s c}^{-1}$ and the intrinsic attenuation $Q_{i}^{-1}$ to obtain information about small-scale heterogeneities of the subsurface in the central area of the Leipzig-Regensburg fault zone (LRZ), Germany (Fig. 1) and compare the two methods concerning their results. Both methods are shown as examples in Fig. 2. The dimensionless quality factor $Q$ describes the loss of relative energy per oscillation cycle. The greater challenge is the distinction between $Q_{i}^{-1}$ and $Q_{s c}^{-1}$. Besides the geometrical spreading, both are main contributors to the total seismic attenuation $Q_{t}^{-1}$.

$Q_{t}^{-1}=Q_{i}^{-1}+Q_{s c}^{-1}$

Intrinsic attenuation describes the conversion of seismic energy into heat or other forms of energy by inelastic processes such as friction while scattering attenuation describes the process of changing the direction of wave propagation or phase shift due to heterogeneities. Another approach to determining attenuation is to measure $Q$ based on coda waves (Aki \& Chouet 1975). The resulting $Q_{c}^{-1}$ is easy to measure, but the physical meaning of $Q_{c}^{-1}$ is controversial since $Q_{c}^{-1}$ depends simultaneously on the scattering and anelastic properties of the crust (Calvet et al. 2013). Only in the multiple scattering regime, for example, at sufficiently long lapse-times, $Q_{c}^{-1}$ is an approximation of $Q_{i}^{-1}$ (Aki \& Chouet 1975). In contrast, the attenuation values $Q_{i}^{-1}$ and $Q_{s c}^{-1}$ depend only on the transport scattering coefficient $g^{*}$ and the absorption coefficient $b$, respectively. The relation is given by (Eulenfeld \& Wegler 2016):

$Q_{s c}^{-1}=\frac{g^{*} v_{0}}{2 \pi f} \quad Q_{i}^{-1}=\frac{b}{2 \pi f}$

(C) The Author(s) 2021. Published by Oxford University Press on behalf of The Royal Astronomical Society. 


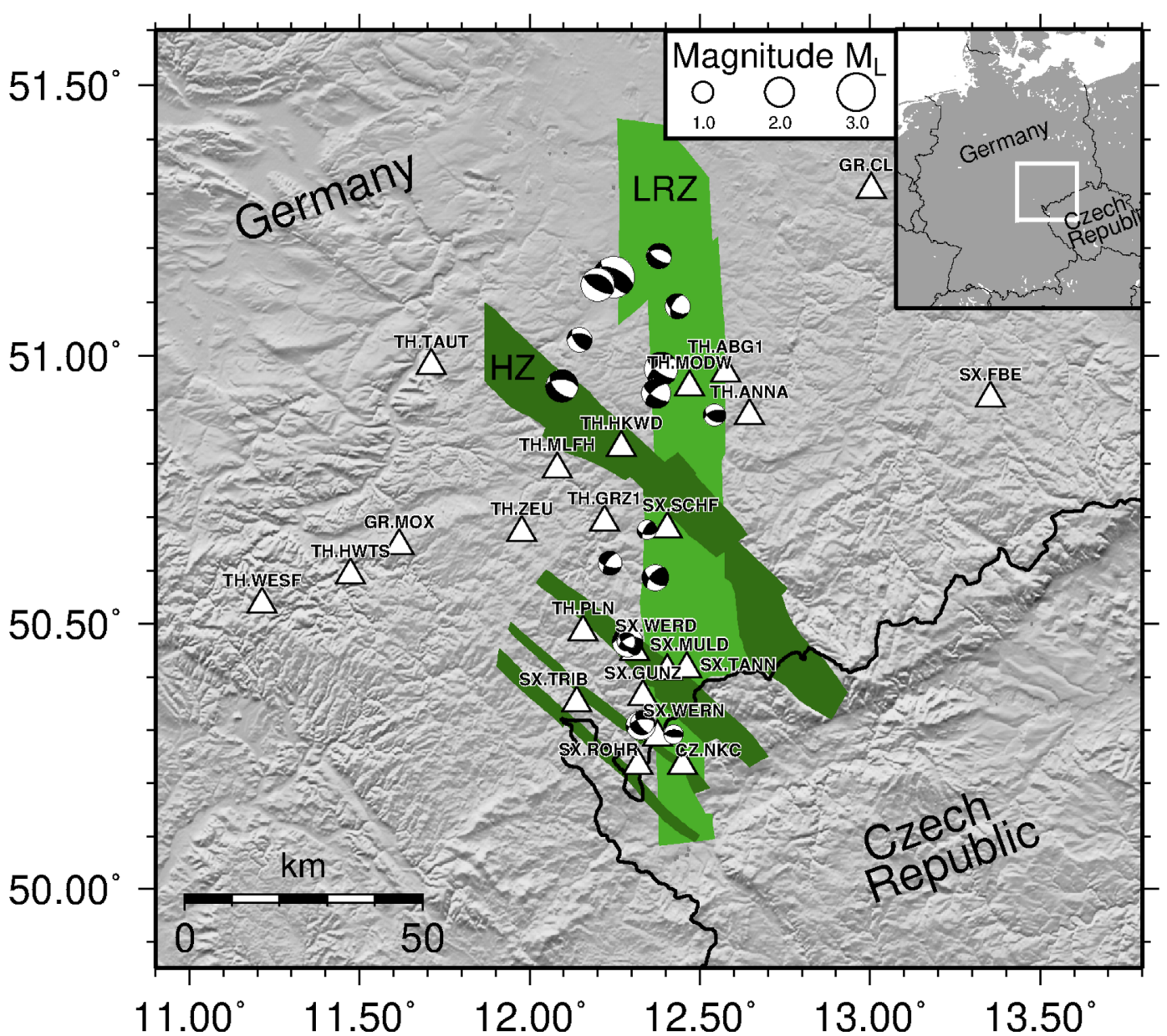

Figure 1. Overview map with hillshade of the survey area. The 18 tectonic earthquakes used for this study are shown with their focal mechanisms, obtained with Grond (Heimann et al. 2018), and with a size corresponding to their magnitude. The area of the N-S striking LRZ is shown in light green and the areas of the NW-SE striking Herzyn fault zones (HZ) as dark green (after LfULG 2018). White triangles display the position of the stations.

with the mean velocity $v_{0}$ and frequency $f$. A power law can often describe the frequency dependence of $Q^{-1}$ :

$Q^{-1}=Q_{0}^{-1} f^{n}$

\section{INVESTIGATION AREA}

The investigation focuses on the crustal structure in the central area of the LRZ (Grünthal et al. 1985). Several NW-SE striking Hercynian fault zones cross the N-S striking LRZ (Pitzsch 1963). A band of seismic activity with an area of about $150 \mathrm{~km}$ length and $40 \mathrm{~km}$ width (Bankwitz et al. 2003) characterize the middle part of the LRZ, with most earthquakes occurring at depths between 4 and $17 \mathrm{~km}$. The southern earthquakes are mainly located in the shallower crustal area, while the northern earthquakes also occur at greater depths. There are also numerous areas of intracontinental earthquake swarms along the southern part of the LRZ (Korn et al. 2008), while the north has no such earthquake swarm areas. In contrast to normal earthquakes with a strong main earthquake and weaker aftershocks, the strongest earthquake of an earthquake swarm does not occur at the beginning but usually later on. Another unique aspect of earthquake swarms is that they actually only occur in areas of extensional tectonics such as mid-ocean rifts or active volcanic areas. However, both phenomena do not occur in this area (Fischer et al. 2014). An analysis of the magnitude distribution and temporal evolution has shown that swarms of the LRZ correspond to the typical values of an earthquake swarm (Neunhöfer 1998; Hemmann et al. 2003). The $b$-values of 73 swarms in the period 1903 to 1999 were analysed by Neunhöfer \& Hemmann (2005) and are in the range of 0.5-1.5. The intensive swarms of 1908, 1962, 1985/86 as well as 1997 and 2000 are very close to a $b$-value of 1 (Neunhöfer \& Hemmann 2005). This value agrees with the observation of Ibs-von Seht et al. (2008), who determined a $b$-value of 0.8 for intracontinental earthquake swarms in non-volcanic areas. Ascending fluids from the subsurface are assumed to be the source of these earthquake swarms (Špičak \& Horálek 2001; Weise et al. 2001; Hofmann et al. 2003; Bräuer et al. 2009; Mousavi et al. 2015). The study area also borders the southern NW-Bohemia/Vogtland region at the German-Czech border, where a large variety of different investigations and methods have been carried out to obtain information on the earthquake swarm activity and crustal structure (Fischer et al. 2014). 


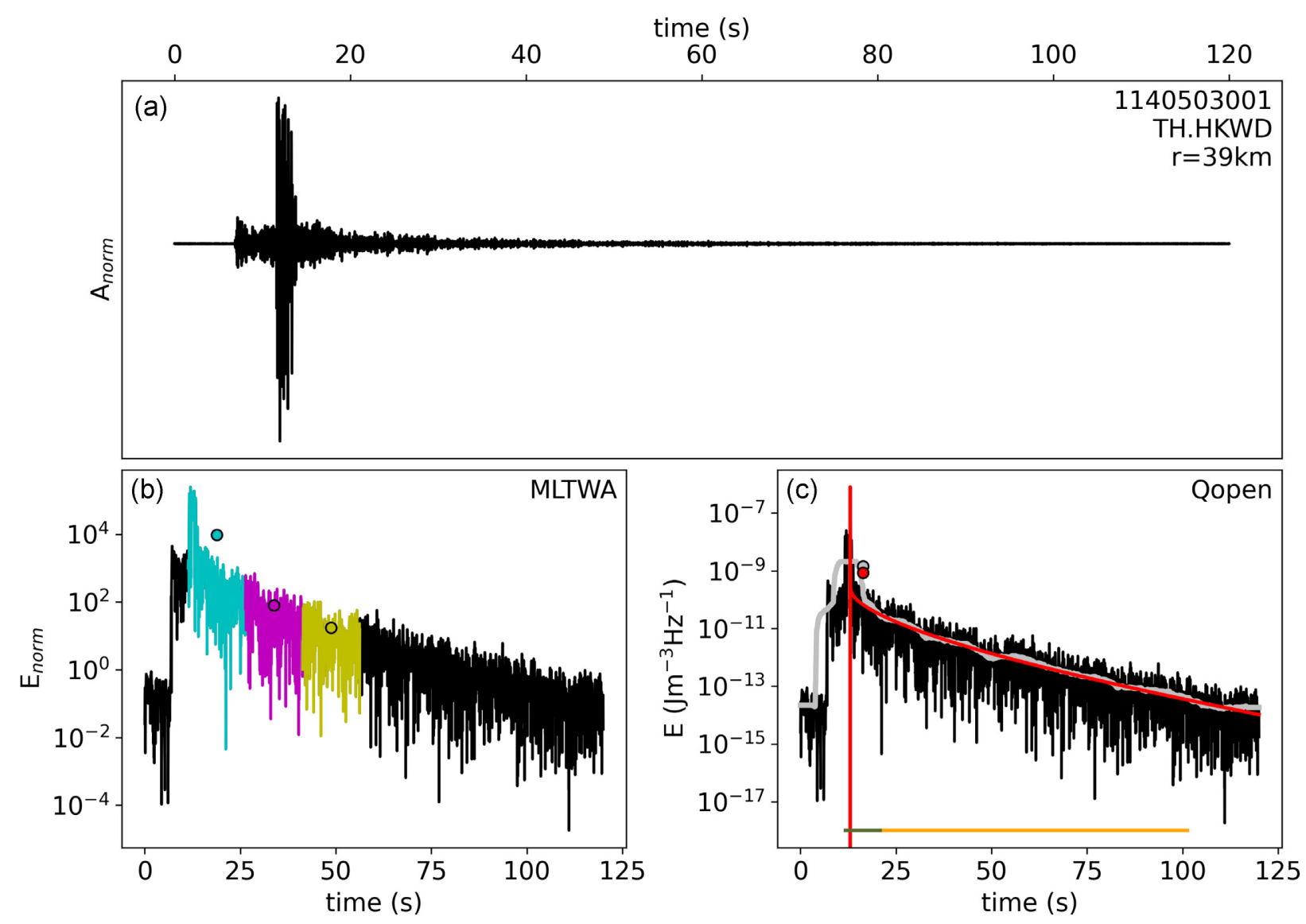

Figure 2. (a) Processed E-component of station HKWD in $39 \mathrm{~km}$ distance to an event (origin time: 2014-05-03T03:46:01.2). The displayed data are tapered, detrended, filtered (4.25-12.75 Hz) and normalized. Bottom: three-component envelope (black) of the station and exemplary representation of the two methods used for this study. (b) MLTWA method with three time windows (cyan, magenta and yellow) of $15 \mathrm{~s}$ length starting from the $S$-arrival time and the corresponding integrated energy (circles). (c) Qopen with the smoothed envelope over $2 \mathrm{~s}$ (grey), the time window of the direct wave (olive) and the coda window (orange) for which the synthetic energy density (red) is calculated using the Green's function. The envelope in the direct wave time window is averaged (circles).

\section{DATA AND METHOD}

\subsection{Data}

We use 18 of the strongest earthquakes (Fig. 1) of the Thüringer Seismologisches Netz (TSN) earthquake catalogue from the period $2008-2019$ and within the coordinates of latitude $50.30^{\circ}-51.19^{\circ}$ and longitude $12.0^{\circ}-12.75^{\circ}$ to determine the attenuation properties in the area of the LRZ. The magnitudes range from 1.4 to 3.0 and the depths from 9.0 to $19.2 \mathrm{~km}$. In total, waveform data were collected at 22 low noise stations (Fig. 1) by the networks Czech Regional Seismic Network (Czech Regional Seismic Network 2019), German Regional Seismic Network (German Regional Seismic Network 2019), Saxon Seismic Network (Saxon Seismic Network 2019) and Thüringer Seismologisches Netz (Thüringer Seismologisches Netz 2019). Each station is equipped with a three-component seismometer, and the seismograms were sampled at a 100 or $200 \mathrm{~Hz}$ rate. Only stations with a distance of less than $90 \mathrm{~km}$ from the earthquake are selected. The seismograms were detrended, tapered to minimize boundary effects and divided by sensitivity. The data is then filtered, and the analysis was performed in eight frequency bands: $1.5-4.5,2.1-6.3,3-9,4.25-12.75,6-18,8.5-25.5,12-36$ and 17-49.9 Hz with the corresponding central frequencies: 3, 4.2, 6, 8.5, 12, 17, 24 and $34 \mathrm{~Hz}$. The data must be available at a minimum of four stations for the appropriate frequency of the event to be considered, and the picks were manually identified with SeismicHandler (Stammler 1993). We calculate the required $S$-wave velocity using the $S$-wave traveltime and distance. The following calculation of the envelopes is based on the square sum of the three components, and the Hilbert transform, as well as the correction of the free surface (Eulenfeld \& Wegler 2016). The last step for Qopen is to smooth the envelope over $2 \mathrm{~s}$. Only seismograms with a good signal-to-noise ratio (SNR) of at least two and sufficient coda length of at least $45 \mathrm{~s}$ starting from the $S$-pick were used for analysis. We used the mean value of a reference time window between 0 and $4 \mathrm{~s}$ before the origin time to calculate the noise level. 


\subsection{Multiple Lapse Time Window Analysis}

Fehler et al. (1992) introduced the MLTWA method for calculating the attenuation property of the subsurface. Further studies have already successfully applied the method (Hoshiba et al. 2001; Giampiccolo et al. 2006; Carcolé \& Sato 2010; Meirova \& Pinsky 2014; Bachura \& Fischer 2016). Since the two attenuation parameters $Q_{i}^{-1}$ and $Q_{s c}^{-1}$ have a different influence on the envelope, the relative energy change of several time windows and over different distances can be used to determine the respective attenuation. The scattering attenuation $Q_{s c}^{-1}$ is mainly responsible for the ratio of energy in different time windows over different distances. For example, strong scattering ensures that most of the energy ends up in the later time windows, while weak scattering ensures that most of the energy ends up in the first time window (Carcolé \& Sato 2010). Intrinsic attenuation $Q_{i}^{-1}$, on the other hand, is responsible for the exponential decay with time of the energy of the seismic wavefield, regardless of the distance (Carcolé \& Sato 2010).

The $S$-wave energy density $E_{\text {syn }}$ in a given frequency band can be described with the equation (Sens-Schönfelder \& Wegler 2006):

$E_{\text {syn }}(t, \mathbf{r})=W R(\mathbf{r}) G\left(t, \mathbf{r}, g^{*}\right) e^{-b t}$

with $t$ the lapse time, $\mathbf{r}$ a vector pointing from the hypocentre to the location of the station, $W$ the spectral $S$-wave source energy of the event, $R$ (r) the energy site amplification of the station, $G\left(t, \mathbf{r}, g^{*}\right)$ the energy density Green's function and the exponent $e^{-b t}$ which describes the intrinsic attenuation with time and depends only on the absorption coefficient $b$. The Green's function considers the direct $S$ - wave and the scattered wavefield, assuming a homogeneous $S$-wave velocity, homogenous attenuation parameters, isotropic scattering and isotropic source radiation pattern. It can be calculated with the analytical approximation solution of the 3-D isotropic energy transfer equation of Paasschens (Paasschens 1997; Eulenfeld \& Wegler 2016):

$$
\begin{aligned}
G\left(t, \mathbf{r}, g^{*}\right)= & \exp \left(-v_{0} \operatorname{tg}^{*}\right)\left[\frac{\delta\left(r-v_{0} t\right)}{4 \pi r^{2}}+\left(\frac{4 \pi v_{0}}{3 g^{*}}\right)^{-\frac{3}{2}} t^{-\frac{3}{2}}\right. \\
& \left.\times\left(1-\frac{r^{2}}{v_{0}^{2} t^{2}}\right)^{\frac{1}{8}} K\left(v_{0} t g^{*}\left(1-\frac{r^{2}}{v_{0}^{2} t^{2}}\right)^{\frac{3}{4}}\right) H\left(v_{0} t-r\right)\right]
\end{aligned}
$$

with

$K(x)=e^{x} \sqrt{1+\frac{2.026}{x}}$

with the Heaviside step function $H$ and $r=|\mathbf{r}|$. The Dirac delta function term $\delta$ of the equation describes the direct wave and the other term the scattered waves. The assumption of isotropic scattering instead of anisotropic scattering is invalid. However, a scattering coefficient $g_{0}$ determined under the assumption of isotropic scattering in an anisotropic scattering medium can be equated to the transport scattering coefficient $g^{*}$ (Gaebler et al. 2015).

By coda normalization of the observed data, the terms $W$ and $R$ (r) of eq. (4) are removed (Aki 1980) and the synthetic energy depends only on the Green's function and the exponent of intrinsic attenuation. The coda normalization factor is the mean value of the energy in a reference time window between 60 and $65 \mathrm{~s}$ after origin time and is calculated separately for each seismogram. The normalization window was chosen as late in the coda as possible but still fulfills the SNR criterion. Afterwards, the envelope is divided into three consecutive time windows of $15 \mathrm{~s}$, starting from the $S$-wave arrival time $t_{s}$ and integrated within the time window:

$E_{1}(\mathbf{r})=\int_{t_{s}}^{t_{s}+15 s} E(t, \mathbf{r}) d t, \quad E_{2}(\mathbf{r})=\int_{t_{s}+15 s}^{t_{s}+30 s} E(t, \mathbf{r}) d t, \quad E_{3}(\mathbf{r})=\int_{t_{s}+30 s}^{t_{s}+45 s} E(t, \mathbf{r}) d t$

Subsequently, the three energy integrals are corrected for the hypocentral distance by multiplying with $4 \pi r^{2}$ resulting in the misfit function $M$ (Bachura \& Fischer 2016) between observed and synthetic data over the three time windows $i$ :

$\left.\left.M\left(Q_{s c}^{-1}, Q_{i}^{-1}\right)=\sum_{k=1}^{N} \sum_{i=1}^{3} w_{i}\left(\log _{10}\left(4 \pi r^{2} E_{o b s_{i}}\left(\mathbf{r}_{\mathbf{k}}\right)\right)\right)-\log _{10}\left(4 \pi r^{2} E_{s y n_{i}}\left(\mathbf{r}_{\mathbf{k}}\right)\right)\right)\right)^{2}$

with $N$ the number of stations of an event. The mistfit function is used individually for each event and frequency band. To minimize the influence of the source radiation characteristics in the direct wave (Bachura \& Fischer 2016), the two later time windows $E_{2}(\mathbf{r})$ and $E_{3}(\mathbf{r})$ are weighted stronger in the inversion with the weighting factor $w=(0.5,1,1)$. We use the brute force method to minimize the misfit function over a range of $Q_{s c}^{-1}=\left[10^{-5}, 10^{-3}\right]$ and $Q_{i}^{-1}=\left[10^{-4}, 10^{-2}\right]$ with 200 points in both dimensions. The final attenuation result is the median of all events and as an error measure, the interquartile range ( 75 th and 25 th percentile) was calculated.

\subsection{Qopen}

The software Qopen is provided by Eulenfeld \& Wegler (2016) and calculates attenuation, source displacement spectra and site amplifications. The programme is based on the radiative transfer theory (RTT) and uses Paaschens equation (Paasschens 1997) to calculate the Green's function. The inversion proceeds as follows: first, the parameters $b, g^{*}, R(\mathbf{r})$ and $W$ from eq. (4) are inverted individually for each frequency 

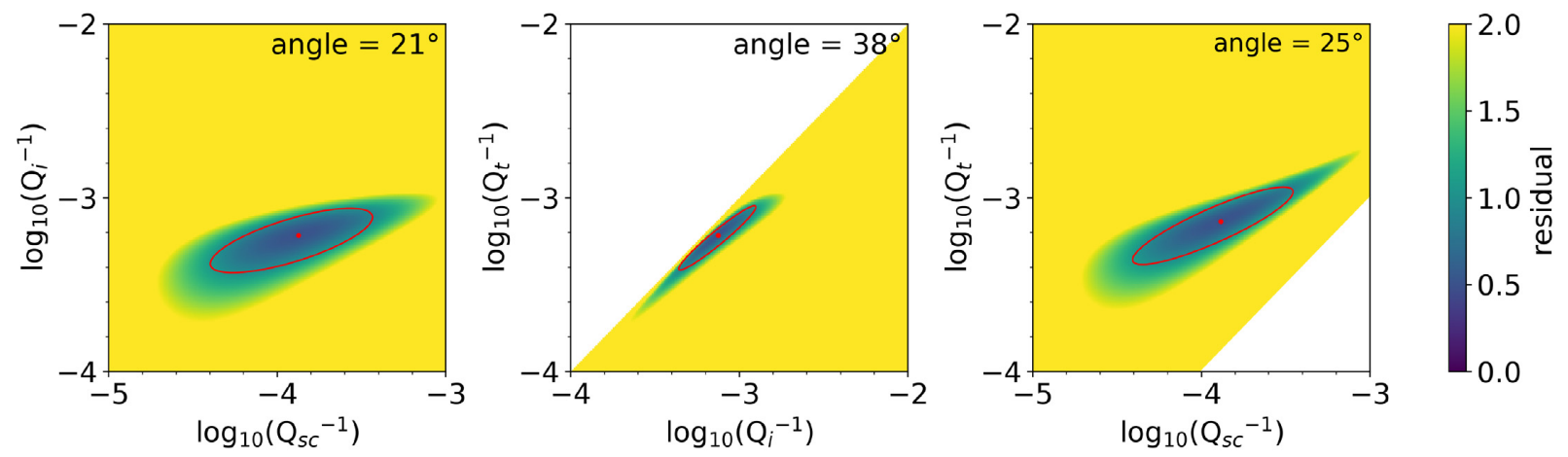

Figure 3. Comparison of the misfit functions of the MLTWA inversion of one event between 6 and $18 \mathrm{~Hz}$ using different inversion parameters. The red dot shows the minimal residual. The red ellipse represents all points with residual $<1$ and a standard deviation of $2 \sigma$. The angle of the ellipse in relation to the $x$-axis results in the trade-off of the inversion parameters, which is lowest for the combination $Q_{s c}^{-1}$ and $Q_{i}^{-1}$.

band and earthquake using the least-squares linear equation system. In the next step, we fix the parameters $b$ and $g^{*}$ and eq. (4) is solved again only for $R(\mathbf{r})$ and $W$ for each frequency band and earthquake individually. To fix the collinearity between $W$ and $R(\mathbf{r})$ from eq. (4), the site amplification of a single station or the geometric mean of site amplification of all stations needs to be fixed and is set to 1 in this study (Eulenfeld \& Wegler 2016). Finally, the source displacement spectra, source parameters and the moment magnitudes are calculated. The further details of the inversion are described in Eulenfeld \& Wegler (2016). The boundaries used for the inversion are $g^{*}=\left[10^{-8}, 10^{-2}\right] \mathrm{m}^{-1}$ and $b=\left[10^{-6}, 1\right] \mathrm{s}^{-1}$. The direct $S$-wave window starts $1 \mathrm{~s}$ before the $S$-wave arrival time and ends $10 \mathrm{~s}$ afterwards. The coda window starts at the end of the direct $S$-wave window and has a maximum length of $120 \mathrm{~s}$ considering an SNR $>2$, where the SNR is determined for each frequency band separately. The length of the time window corresponds to the weighting of the station in the inversion. Station data with a coda shorter than $35 \mathrm{~s}$ was not considered for the inversion. The separation of the envelope into two different time windows (direct wave and coda) is necessary because the effects of anisotropic scattering near the $S$-wave cannot be described correctly by the acoustic Green's function assuming isotropic scattering. The problem can be solved by more complex methods, such as elastic Monte-Carlo simulation with Born scattering coefficients (Przybilla et al. 2006; Sens-Schönfelder et al. 2009; Gaebler et al. 2015).

We added the option of coda normalization to Qopen to better compare to coda normalized MLTWA. In this case, only the parameters $b$ and $g_{0}$ are inverted, and this step eliminates information about source displacement spectra and site amplifications.

\section{RESULTS}

\subsection{MLTWA}

We tested various combinations of inversion parameters to identify the lowest trade-off between $Q_{i}^{-1}, Q_{s c}^{-1}$ and $Q_{t}^{-1}$. Fig. 3 shows the misfit functions for three different combinations, providing information about model validity and data processing suitability. The misfit function should be parallel to one of the axes to restrict at least one inversion parameter. The more parallel the misfit function is, the lower the trade-off between the two inversion parameters is in the end. Still, one of the two inversion parameters remains stable over a wide range, resulting in uncertainty for this parameter. As a result, the combination of $Q_{i}^{-1}$ and $Q_{s c}^{-1}$ gives the least trade-off compared to the parameter combinations of $Q_{i}^{-1}$ and $Q_{t}^{-1}$ and $Q_{s c}^{-1}$ and $Q_{t}^{-1}$.

The comparison between observed and synthetic data is shown in Fig. 4 averaged over all events. Due to the direct $S$-wave's strong influence on the first time window, the observed values scatter strongly for $E_{1}$, and the radiation pattern behaviour of the earthquake becomes notable here as the coda normalization cannot completely eliminate the effect. However, the radiation pattern's influence on the attenuation's determination is minimal since the station distribution covers a wide azimuthal range. In contrast, the time windows $E_{2}$ and $E_{3}$ show a good agreement between observed and synthetic data.

\subsection{Qopen}

An essential point in the inversion of Qopen is the choice of the time window length of the coda window. Short time windows result in an imprecise estimation of attenuation parameters and trade-off. Long time windows possibly might not be realized due to the noise level. Therefore, it is crucial to find a balance between these two aspects. We have investigated the window length's influence on the inversion (Fig. 5). For this purpose, the data were inverted several times with coda time windows of various lengths, and the mean values of all events were compared. We fixed all inversion parameters with a direct wave window of $10 \mathrm{~s}$. The coda window successively increases in steps of $5 \mathrm{~s}$, starting from a coda window length of $10 \mathrm{~s}$ up to $65 \mathrm{~s}$. The length of the longest coda window was chosen in a way to extend until the normalization time window in MLTWA. The window's length always corresponds exactly to the specified value, even if the SNR would allow a longer coda time window. Seismograms with shorter time windows due to low SNR were removed from this test. As a result, less and less 

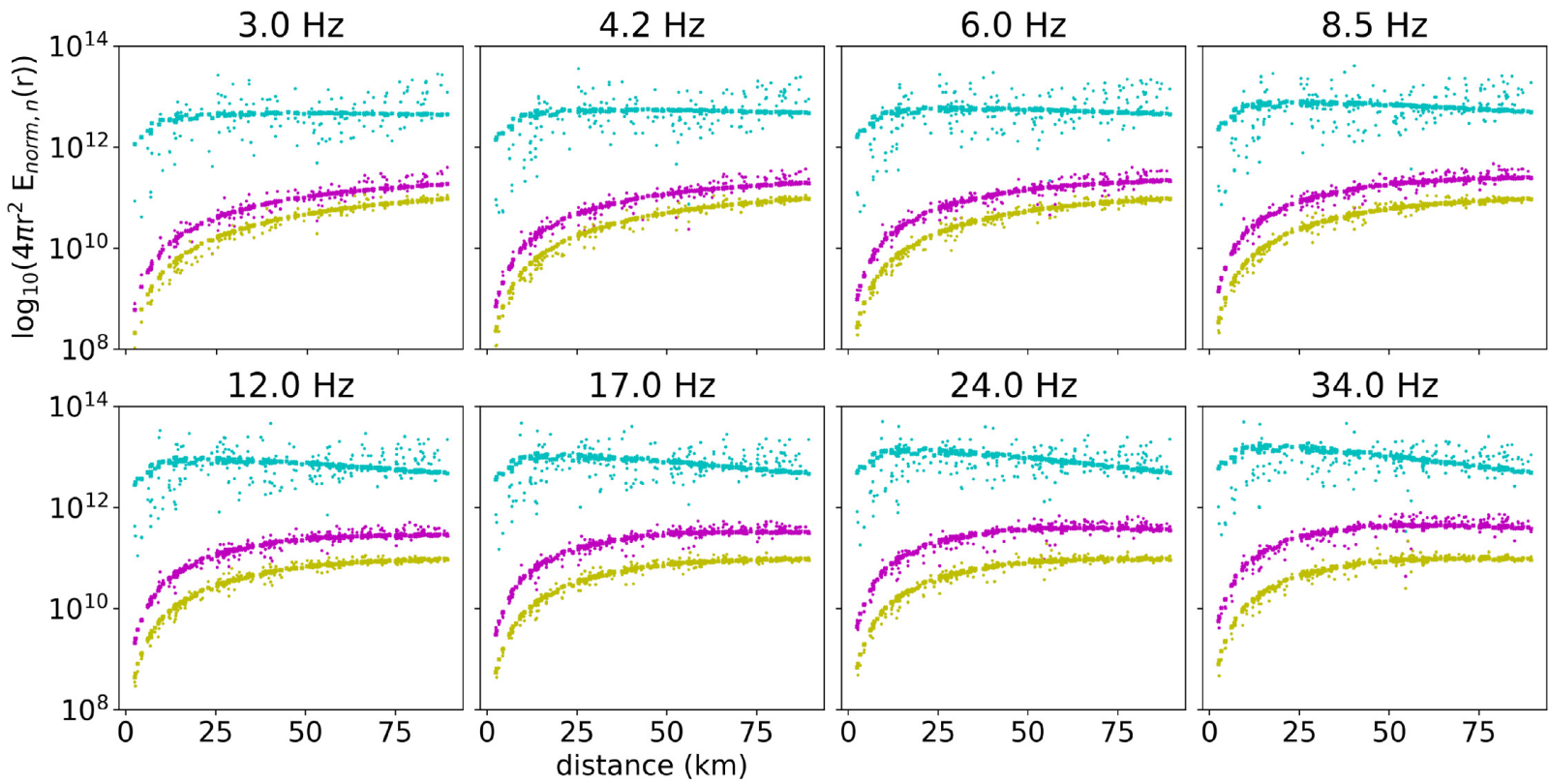

Figure 4. Comparison of synthetics (crosses) and observed (dots) energy versus hypocentral distance of all events of the MLTWA. The colours cyan, magenta and yellow represents the three time windows $E_{1}, E_{2}$ and $E_{3}$ respectively.
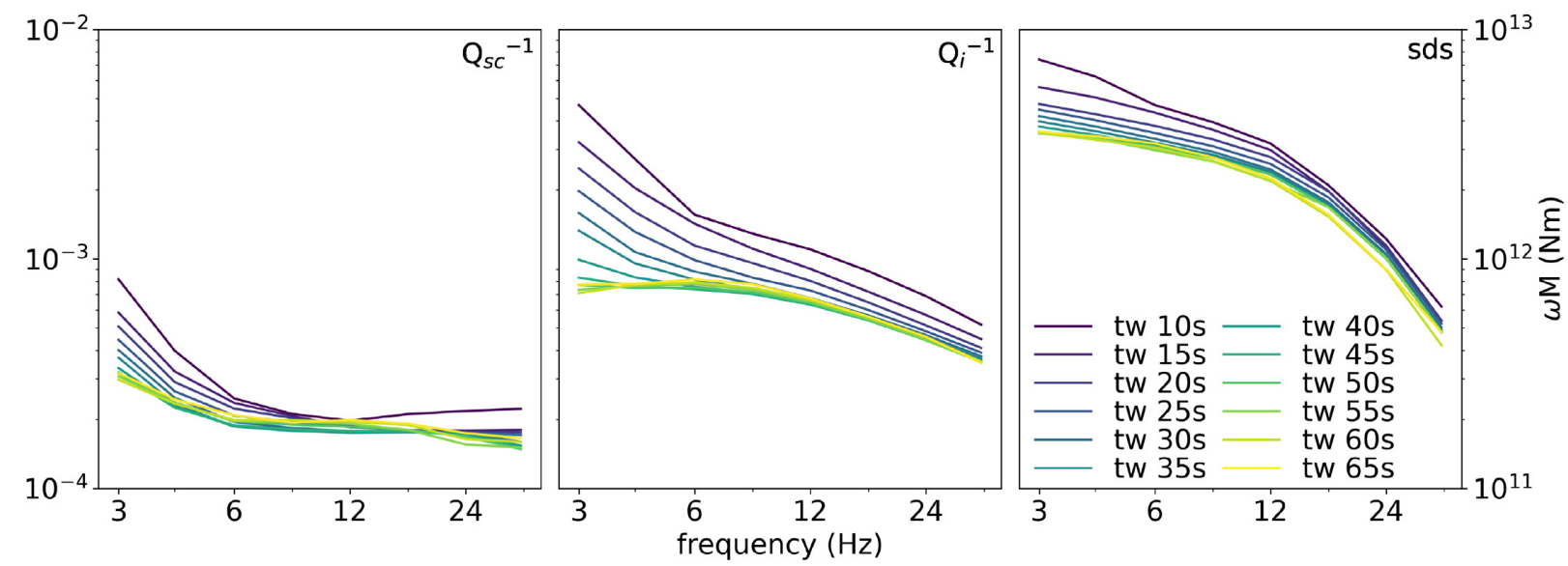

Figure 5. Comparison of $Q_{s c}^{-1}, Q_{i}^{-1}$ and source displacement spectrum (sds) calculated with Qopen and averaged over eight events for different time window (tw) lengths. Since long coda time windows are required, we reduced the data set to the strongest events. The start time of the time windows is always the same. For short time windows, there is a trade-off between increased source displacement spectra and $Q_{i}^{-1}$. With sufficiently long time windows of about $30 \mathrm{~s}$, the trade-off disappears, and $Q_{i}^{-1}$ and source displacement spectrum become independent of the window length.

data were available for the inversion as the length increased. The data set of 18 events was reduced to the eight strongest events for this specific analysis to ensure that in the end, all events are inverted, and the data remains comparable. Thus, the same number of seismograms is inverted in all time windows and only in the last two time windows, the number of seismograms reduced from 64 to 62 . The analysis of the different time windows shows a trade-off between $Q_{i}^{-1}$ and the source displacement spectra. With a sufficient coda length of about $30 \mathrm{~s}$, the trade-off between $Q_{i}^{-1}$ and source displacement spectra disappears, and the results of Qopen remain stable and are independent of the window length. The influence of the coda window length on $Q_{s c}^{-1}$ is minimal, only for very short time windows of 10 and $15 \mathrm{~s}$ the inversion provides larger $Q_{s c}^{-1}$ values compared to the other time windows. The reason for the different results between short and long coda time windows is exemplified in Fig. 6. The inverted parameters $g^{*}$ and $b$ differs greatly ( $10 \mathrm{~s} \mathrm{coda}$ window (red): $g^{*}=9.2 \times 10^{-6} \mathrm{~m}^{-1}$ and $b=9.6 \times 10^{-2} \mathrm{~s}^{-1} ; 120 \mathrm{~s}$ coda window (blue): $g^{*}=3.3 \times 10^{-6} \mathrm{~m}^{-1}$ and $b=3.6 \times 10^{-2} \mathrm{~s}^{-1}$ ) and explain the discrepancy in attenuation values between the different length of coda time windows. Examining the short time window of $10 \mathrm{~s}$ (red bar), one can see that the two synthetic envelopes correspond to the real data about equally well, the envelope of the short time window is slightly above, while the envelope of the long time window slightly below the observed data. However, looking at the later part of the coda, the envelope of the short time window decreases more than the observed data, while the envelope of the long coda time window still fits the observed data. The shorter coda time windows are too short to determine an independent $Q_{i}^{-1}$ and source displacement spectra. 


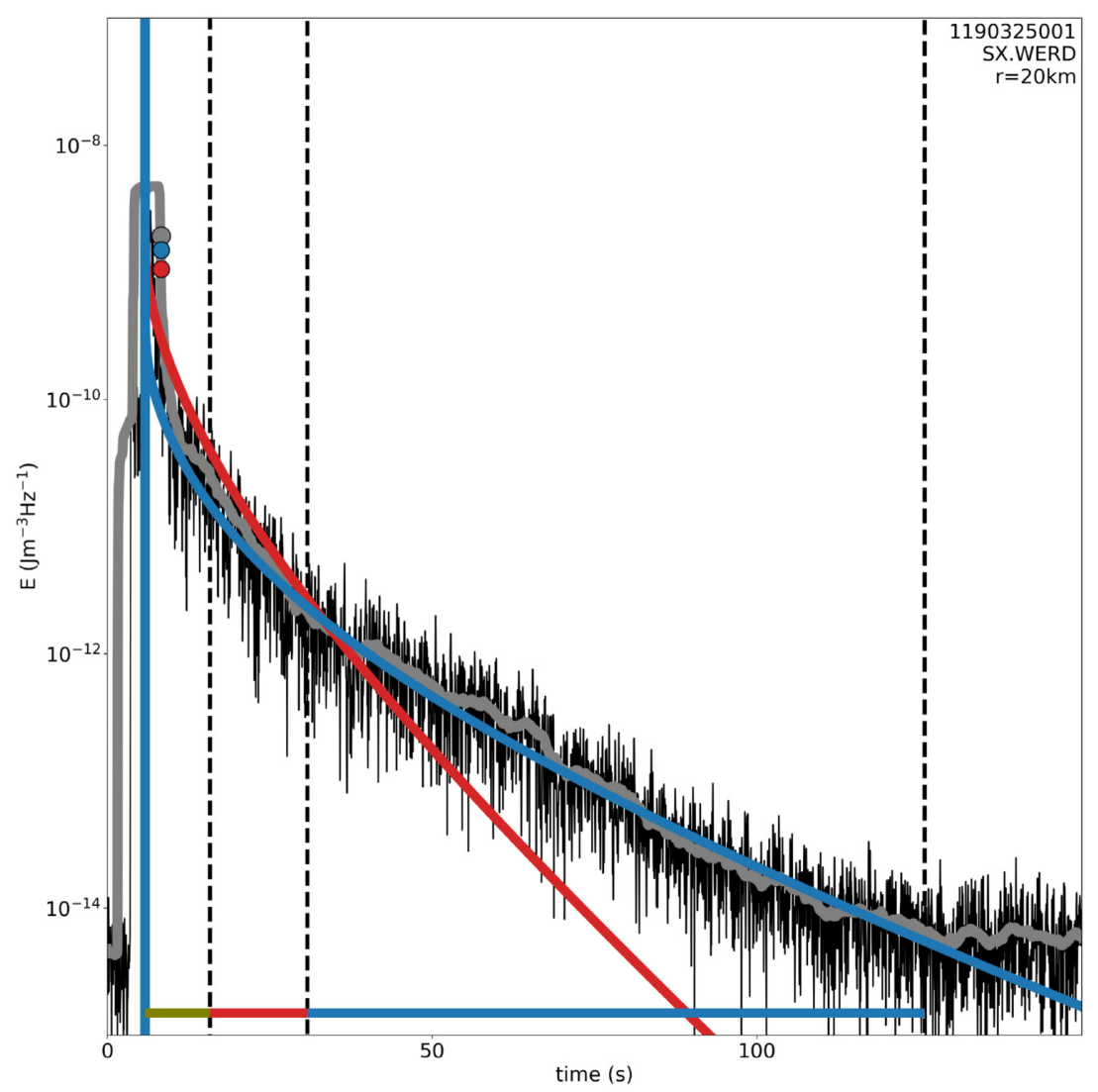

Figure 6. Fit at Station SX.WERD out of 13 stations between observed (black), smoothed observed envelope (grey) and synthetic energy densities of Qopen with different coda window lengths (red $10 \mathrm{~s}$ and blue $120 \mathrm{~s}$ ). The dots show the energy of the direct wave in the respective colour. The bar below the envelope represents the section used for Qopen, respectively.

The increase of $Q_{s c}^{-1}$ and the flattening of $Q_{i}^{-1}$ at low frequencies between 3 and $6 \mathrm{~Hz}$ at Fig. 5 can be explained by an imprecise fit of the envelope in this frequency range and a smaller amount of available data. Therefore, the error is much larger than the high frequencies values, which explains the deviation at the low frequencies from the expected power law for $Q_{i}^{-1}$. We suggest to configure Qopen to use a long coda time window, that is, extend until $100 \mathrm{~s}$ after $S$-onset, and cut the time window earlier depending on SNR ratio. The suggested $100 \mathrm{~s}$ long coda window is an upper limit for studies on a regional scale (e.g. Eulenfeld \& Wegler 2017). For local studies with shorter event-station distances, the coda window should be around 30-50 s long. The direct wave window should be chosen sufficiently long to include the onset and forward scattered waves. Depending on the extent of the study region, its length should be around 4-10 s.

As a by-product of the Qopen inversion, the source displacement spectra (Fig. 7), the moment magnitude $M_{\mathrm{W}}$ (Fig. 8) and the site amplification (Fig. 9) are determined. According to Sato et al. (2012), the source displacement spectra $\omega M(f)$ of a double-couple in the far-field can be calculated by:

$\omega M(f)=\sqrt{\frac{5 \rho_{0} v_{0}^{5} W(f)}{2 \pi f^{2}}}$

with the density $\rho_{0}$. The average corner frequency of all events is $11.4 \mathrm{~Hz}$, and the average high-frequency fall-off is 1.8 . Thereby, the corner frequency corresponds to the typical corner frequency of local earthquakes and the high-frequency fall-off machtes approximately the $\omega^{2}$-model.

The relationship between $M_{0}$ (in Nm) and $M_{\mathrm{W}}$ can be described by (Hanks \& Kanamori 1979):

$M_{\mathrm{W}}=\frac{2}{3} \log _{10} M_{0}-6.07$

The inverted moment magnitudes $M_{\mathrm{W}}$ mostly correspond well to the local magnitudes $M_{\mathrm{L}}$ of the earthquake catalogue (Fig. 8). Nevertheless, with decreasing magnitude, the difference between the determined $M_{\mathrm{W}}$ and the given $M_{\mathrm{L}}$ increases. Various studies have shown that the local magnitude starting at $M_{\mathrm{L}}<2$ does not correspond to $M_{\mathrm{W}}$ (e.g. Deichmann 2006; Bethmann et al. 2011), a linear fit is needed to convert the magnitudes. Deichmann (2006) conducted a theoretical study on this and concluded that systematic and random errors in the determination of $M_{\mathrm{L}}$ lead to the difference between $M_{L}$ and $M_{\mathrm{W}}$, while the study by Bethmann et al. (2011) proves this with real data and uses the modified ray theoretical representation for the displacement of a heterogeneous elastic medium to determine the seismic moment. 


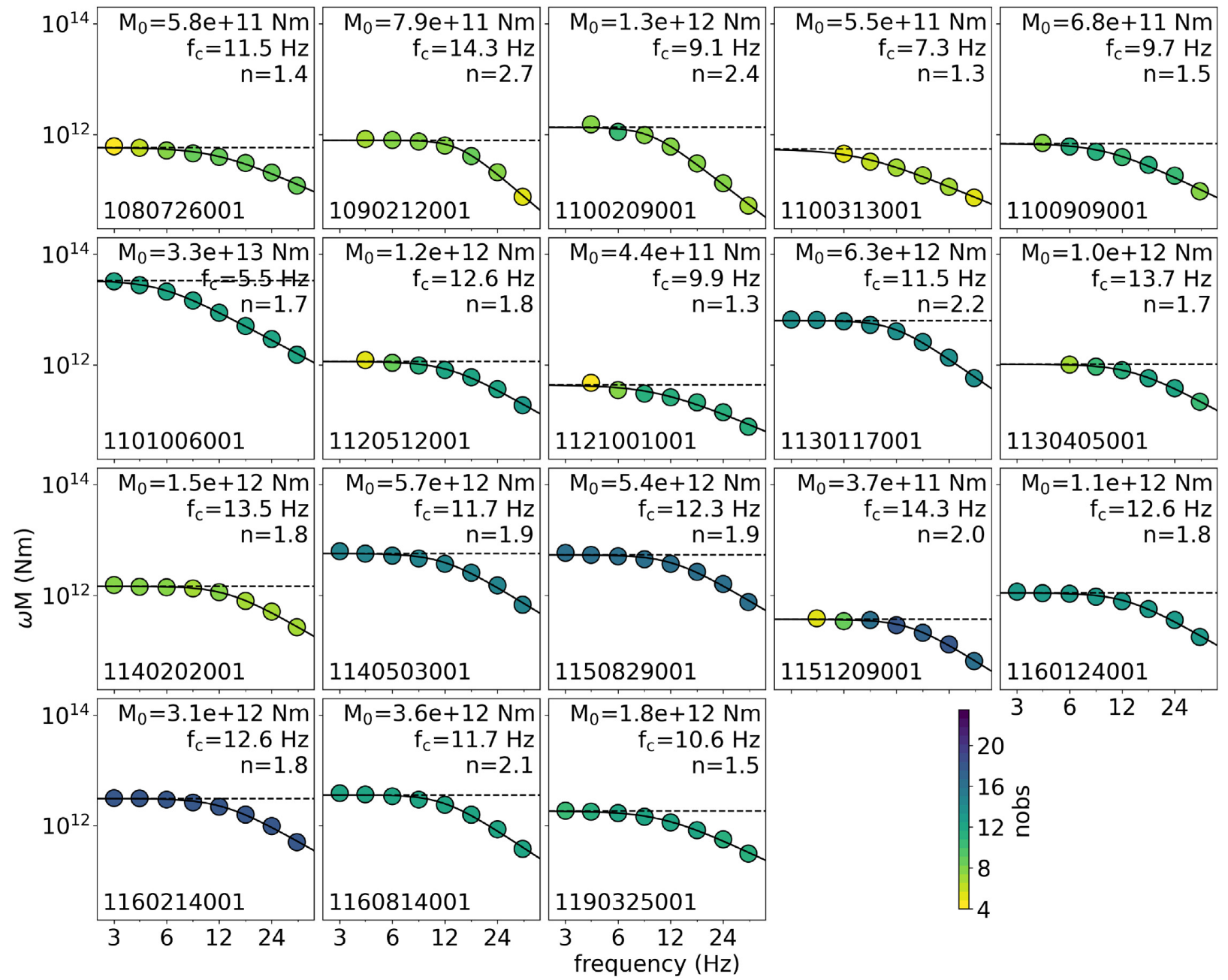

Figure 7. Observed source displacement spectra, displayed as circles depending on the number of observations (nobs) and fitted source model (black lines) for each inverted event. Also, the seismic moment $M_{0}$, the corner frequency $f_{c}$ and the high-frequency fall-off $n$ were determined.

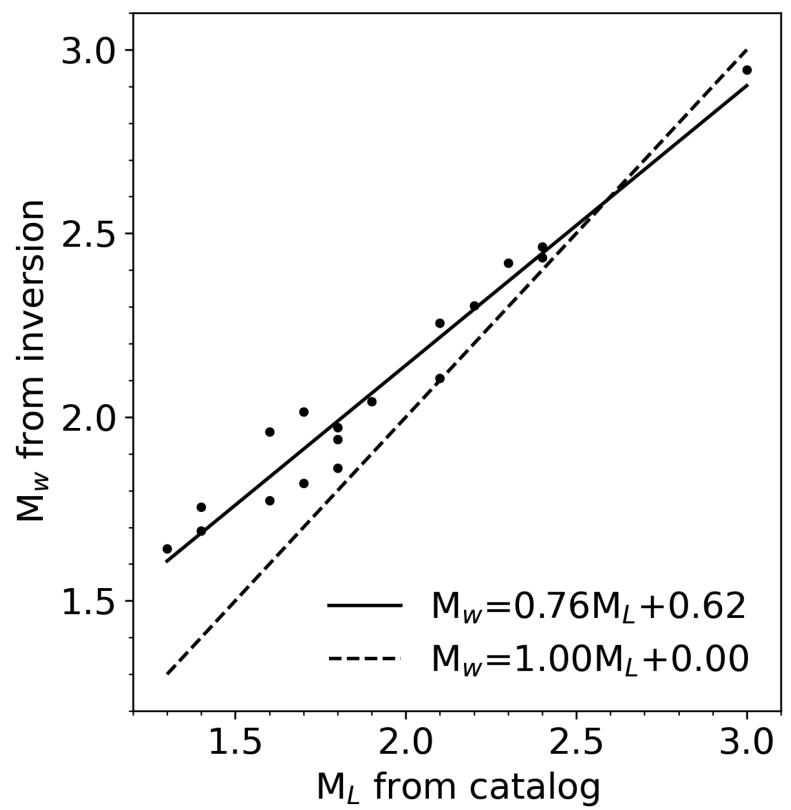

Figure 8. Comparison of catalogue local magnitude $M_{\mathrm{L}}$ and moment magnitude $M_{\mathrm{W}}$ estimated during the inversion. 


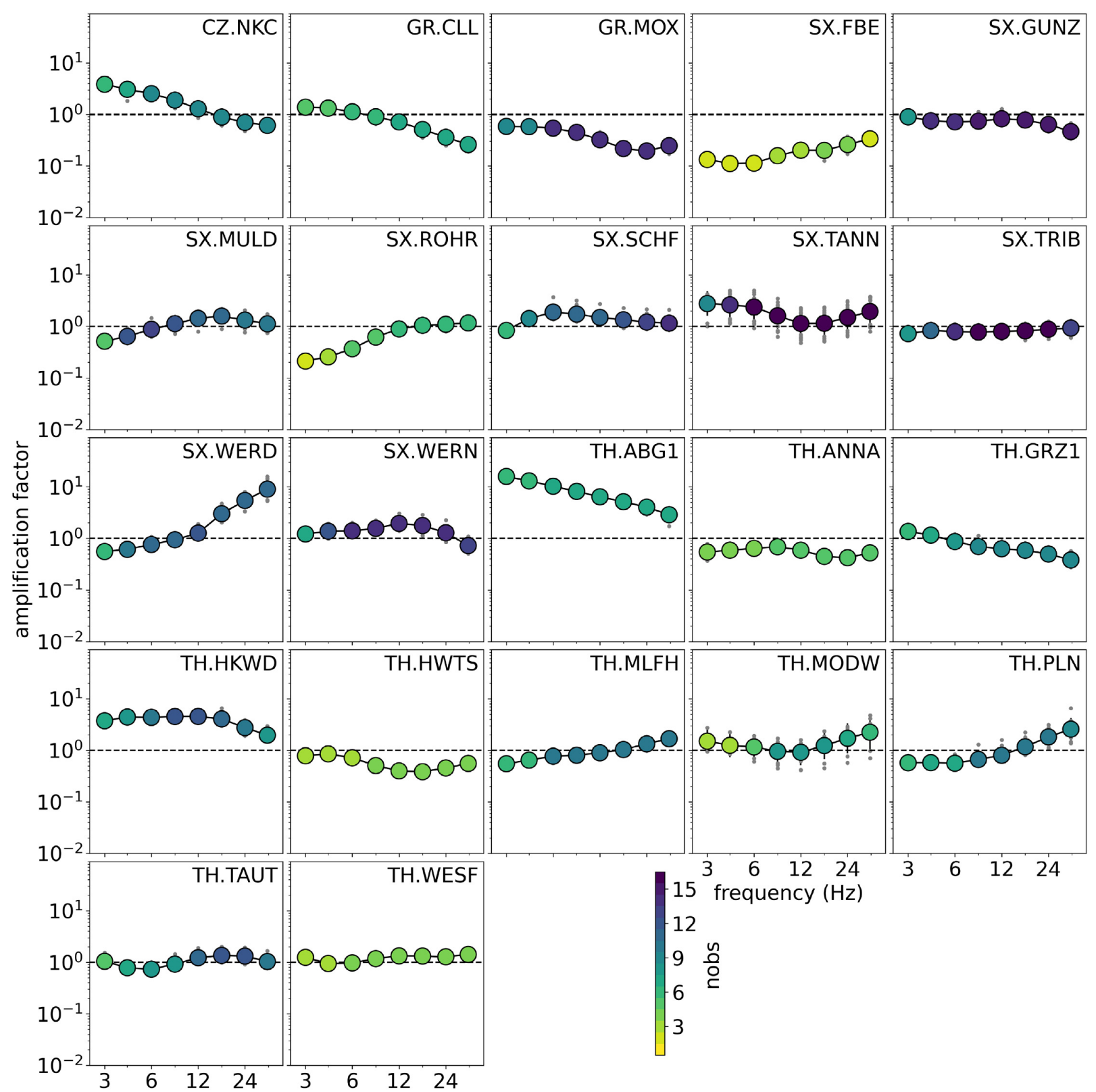

Figure 9. Inverted site amplification of each station. Grey dots indicate the result for individual measurements of one event. The coloured circles represent the median and the number of events used in the corresponding frequency.

The site amplification (Fig. 9) depends on the material near the surface and can vary greatly over short distances. Stations located on sedimentary rocks usually have a site amplification factor greater than 1 , whereas stations located below the surface usually exhibit a factor below 1. Especially the stations AGB1, FBE, HKWD, MOX and WERD stand out among the site amplification. Station AGB1 is located on sediments, explaining the much larger site amplification factor. MODW, which is also on sediment, has a much smaller value in the range of 1. The low values of ANNA, FBE and MOX can be explained by the location in an adit below the surface, while TANN, which is also in an adit, shows higher values. The location of all other stations is on the surface. The reasons for the last two conspicuous site amplification, at station WERD, where site amplification increases strongly at high frequencies, and at station HKWD, which generally shows high values, are unknown. It should also be noted that MODW and TANN's values are largely scattered, leading to errors greater than those for other stations.

\subsection{Comparison of methods and other studies}

A fit between synthetic and observed data of an event with $M_{\mathrm{L}}=2.4$ and the central frequency of $8.5 \mathrm{~Hz}$ is shown in Fig. 10 for the nine closest stations. Eq. (4) was used to calculate the synthetic envelopes. The envelope of the MLTWA was normalized using the mean value of the time window 60-65 s after the origin time of the observed data. The energy of the direct wave of the MLTWA was calculated analogously 


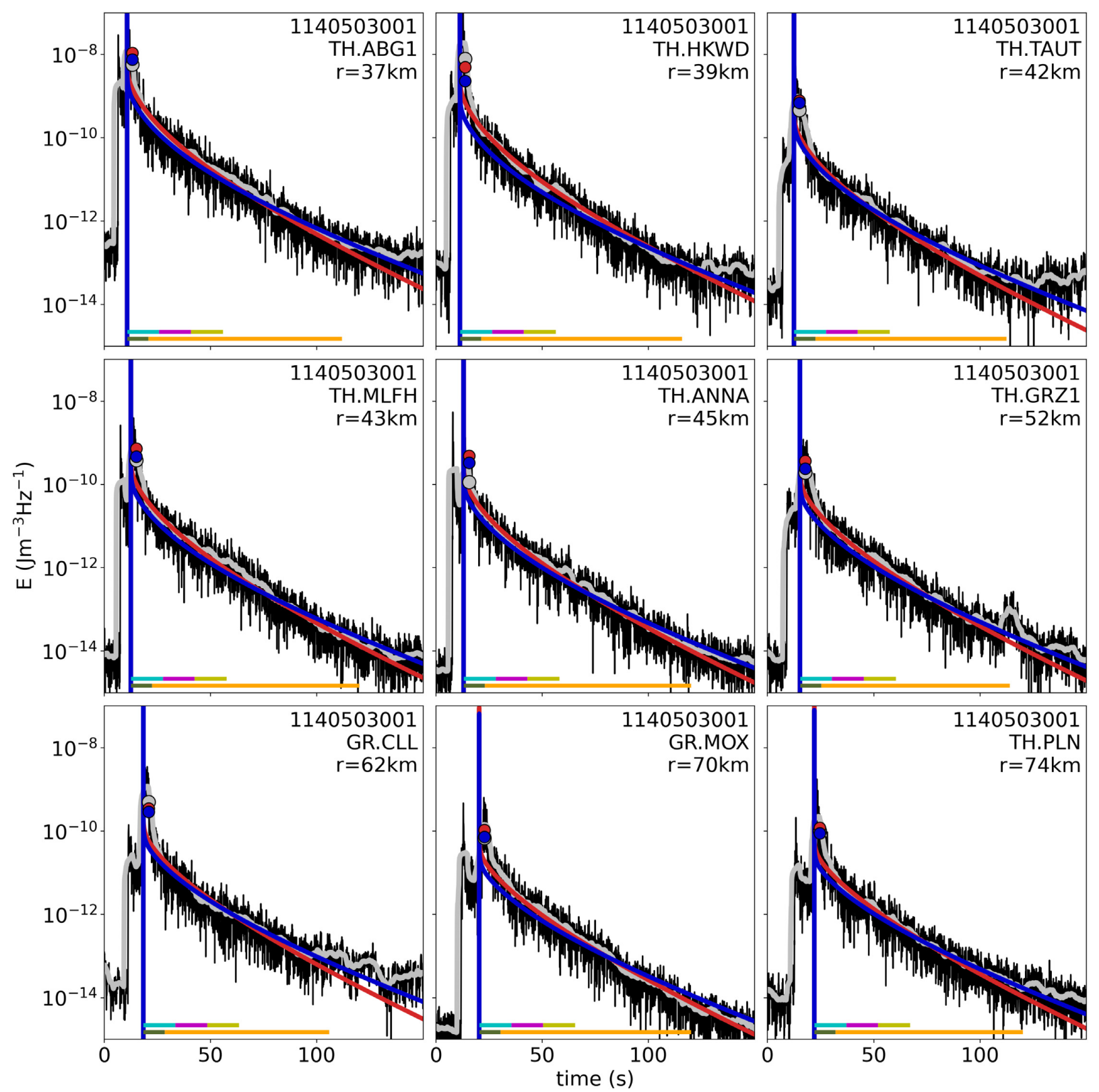

Figure 10. Fits between observed (black), smoothed observed envelope (grey) and synthetic energy densities of the inversion of MLTWA (blue line) and Qopen (red line) of an event $\left(M_{\mathrm{L}} 2.4, M_{\mathrm{W}} 2.45\right)$ in the frequency band $4.25-12.75 \mathrm{~Hz}$. The dots show the energy of the direct wave in the respective colour. The bar below the envelope represents the section used for the MLTWA and Qopen, respectively. Cyan, magenta and yellow indicate the three energy windows of the MLTWA and olive and orange the direct wave and coda window used for Qopen. Only the nine stations closest to the event are shown here.

to Qopen. The attenuation values were determined using only data from this event and are $6.5 \times 10^{-4}$ and $8.5 \times 10^{-4}$ for $Q_{i}^{-1}$ and $1.2 \times$ $10^{-4}$ and $1.6 \times 10^{-4}$ for $Q_{s c}^{-1}$ for MLTWA and Qopen, respectively. Both methods show equally good fits, both for the direct wave window and the coda window. Depending on the station, sometimes Qopen and sometimes the MLTWA provides the best result. Overall, the observed data can be described well by the modelled data under the assumption of RTT with multiple isotropic scattering with the exception of the direct wave. The determined scattering attenuation and intrinsic attenuation of the different methods are shown in Fig. 11 and Table 1. Qopen and the coda normalized version of Qopen, Qopen ${ }^{c n}$, provide similar results. Likewise, the results of MLTWA and Qopen are similar within their errors. However, a comparison of the error bars shows that the error of Qopen at $Q_{s c}^{-1}$ are smaller than for the MLTWA. For $Q_{i}^{-1}$, both methods have errors of about the same size. A further reduction of the error would be achieved using the elastic wave theory or the elastic energy transfer theory instead of the acoustic energy transfer theory (e.g. Gaebler et al. 2015; Emoto et al. 2017). However, these may take much more computation time. An equal weighting of all three time windows of the MLTWA inversion would result in about 4 per cent lower values for $Q_{i}^{-1}$ and $Q_{s c}^{-1}$ and a coda normalized Qopen inversion with $45 \mathrm{~s}$ time window length and weighting of the bulk window of 0.5 

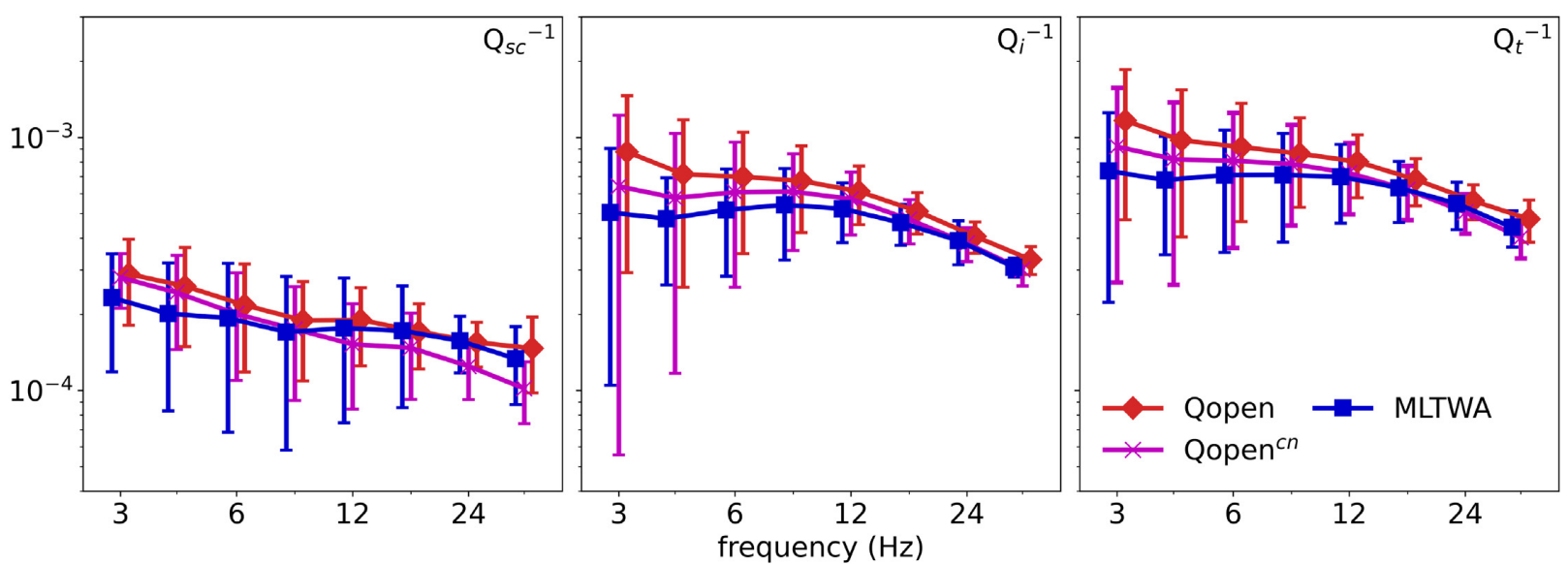

Figure 11. Comparison of the results of $Q_{s c}^{-1}, Q_{i}^{-1}$ and $Q_{t}^{-1}$ with the interquartile range (75th and 25th percentile) as error of the different methods. The frequency values are slightly shifted for better presentation.

Table 1. Crustal scattering and intrinsic attenuation parameters.

\begin{tabular}{lcccc}
\hline & \multicolumn{2}{c}{ MLTWA } & \multicolumn{2}{c}{ Qopen } \\
Frequency (Hz) & $Q_{i}^{-1}$ & $Q_{s c}^{-1}$ & $Q_{i}^{-1}$ & $Q_{s c}^{-1}$ \\
\hline 3 & $5.0 \times 10^{-4}$ & $2.3 \times 10^{-4}$ & $8.7 \times 10^{-4}$ & $2.8 \times 10^{-4}$ \\
4.2 & $4.7 \times 10^{-4}$ & $2.0 \times 10^{-4}$ & $7.1 \times 10^{-4}$ & $2.5 \times 10^{-4}$ \\
6 & $5.1 \times 10^{-4}$ & $1.9 \times 10^{-4}$ & $6.9 \times 10^{-4}$ & $2.1 \times 10^{-4}$ \\
8.5 & $5.4 \times 10^{-4}$ & $1.7 \times 10^{-4}$ & $6.7 \times 10^{-4}$ & $1.8 \times 10^{-4}$ \\
12 & $5.2 \times 10^{-4}$ & $1.8 \times 10^{-4}$ & $6.1 \times 10^{-4}$ & $1.8 \times 10^{-4}$ \\
17 & $4.6 \times 10^{-4}$ & $1.7 \times 10^{-4}$ & $5.1 \times 10^{-4}$ & $1.7 \times 10^{-4}$ \\
24 & $3.9 \times 10^{-4}$ & $1.5 \times 10^{-4}$ & $4.0 \times 10^{-4}$ & $1.5 \times 10^{-4}$ \\
34 & $3.0 \times 10^{-4}$ & $1.3 \times 10^{-4}$ & $3.2 \times 10^{-4}$ & $1.4 \times 10^{-4}$ \\
\hline
\end{tabular}

would result in 8 per cent lower values of $Q_{i}^{-1}$ and 13 per cent lower values for $Q_{s c}^{-1}$. Therefore, although the difference between the methods is slightly larger, the systematic errors are still smaller than the error bars.

The inverse quality factor is monotonically decreasing for both the scattering attenuation and the intrinsic attenuation, only at low frequencies of $Q_{i}^{-1}$ there is a slight flattening. In this context, the results of Qopen are more in line with the power law than the results of MLTWA. The reason for the slight flattening at low frequencies might be, on the one hand, an imprecise fitting of the envelope due to shorter time windows and, on the other hand, a small amount of data due to the SNR criterion. As a result, the error bars at low frequencies are significantly larger than at high frequencies. A comparison between the two attenuations also shows that the error bars of $Q_{i}^{-1}$ are significantly smaller than the error bars of $Q_{s c}^{-1}$ for both methods. The comparison of the absolute values of the attenuation shows that in the study area, $Q_{i}^{-1}$ has significantly larger values than $Q_{s c}^{-1}$, implying intrinsic attenuation dominates in the study area. Gaebler et al. (2015) provide a similar result for the NW-Bohemia/Vogtland region (Fig. 12) which lies only a few kilometres south of our investigation area. Again, intrinsic attenuation dominates over scattering attenuation. However, the inverse quality factors of Gaebler et al. (2015) are higher than the values of this study by a factor between 2 and 8 , indicating some spatial heterogeneity of attenuation within the region. The frequency dependence of the total attenuation is described by the power law (eq. 3) and yields the best fit at $Q_{s c}^{-1} \propto f^{-0.28}, Q_{i}^{-1} \propto f^{-0.37}$ and $Q_{t}^{-1} \propto f^{-0.35}$ for Qopen and $Q_{s c}^{-1} \propto f^{-0.20}, Q_{i}^{-1} \propto f^{-0.17}$ and $Q_{t}^{-1} \propto f^{-0.18}$ for MLTWA. Comparing the power laws of both methods, they provide similar values for $Q_{s c}^{-1}$. However, there are differences for $Q_{i}^{-1}$, due to the flattening of the intrinsic attenuation at low frequencies of MLTWA. Compared to the LRZ, the values of the NW-Bohemia/Vogtland region are $Q_{s c}^{-1} \propto f^{-0.71}, Q_{i}^{-1} \propto f^{-0.93}$ and $Q_{t}^{-1} \propto f^{-0.86}$, respectively. Using the exponent $n$ of the frequency dependence (eq. 3) of $Q_{s c}^{-1}$ the Hurst parameter $\kappa$ can be calculated with $n=-2 \kappa$, describing the roughness of a medium (Sato et al. 2012). With Qopen, this parameter is $\kappa=0.14$ and thus only about half as large as the result of Gaebler et al. (2015) of the neighbouring NW-Bohemia/Vogtland region with $\kappa=0.36$. The difference in the Hurst parameter between NW-Bohemia/Vogtland and LRZ has the same cause as the difference in the power law between Qopen and MLTWA. The study of Gaebler et al. (2015) uses low frequencies which have a strong influence on the slope of the power law (Fig. 12). Looking only at the mid and high frequencies above $6 \mathrm{~Hz}$, the decrease of the attenuation values over the frequencies is similar to the LRZ region. 

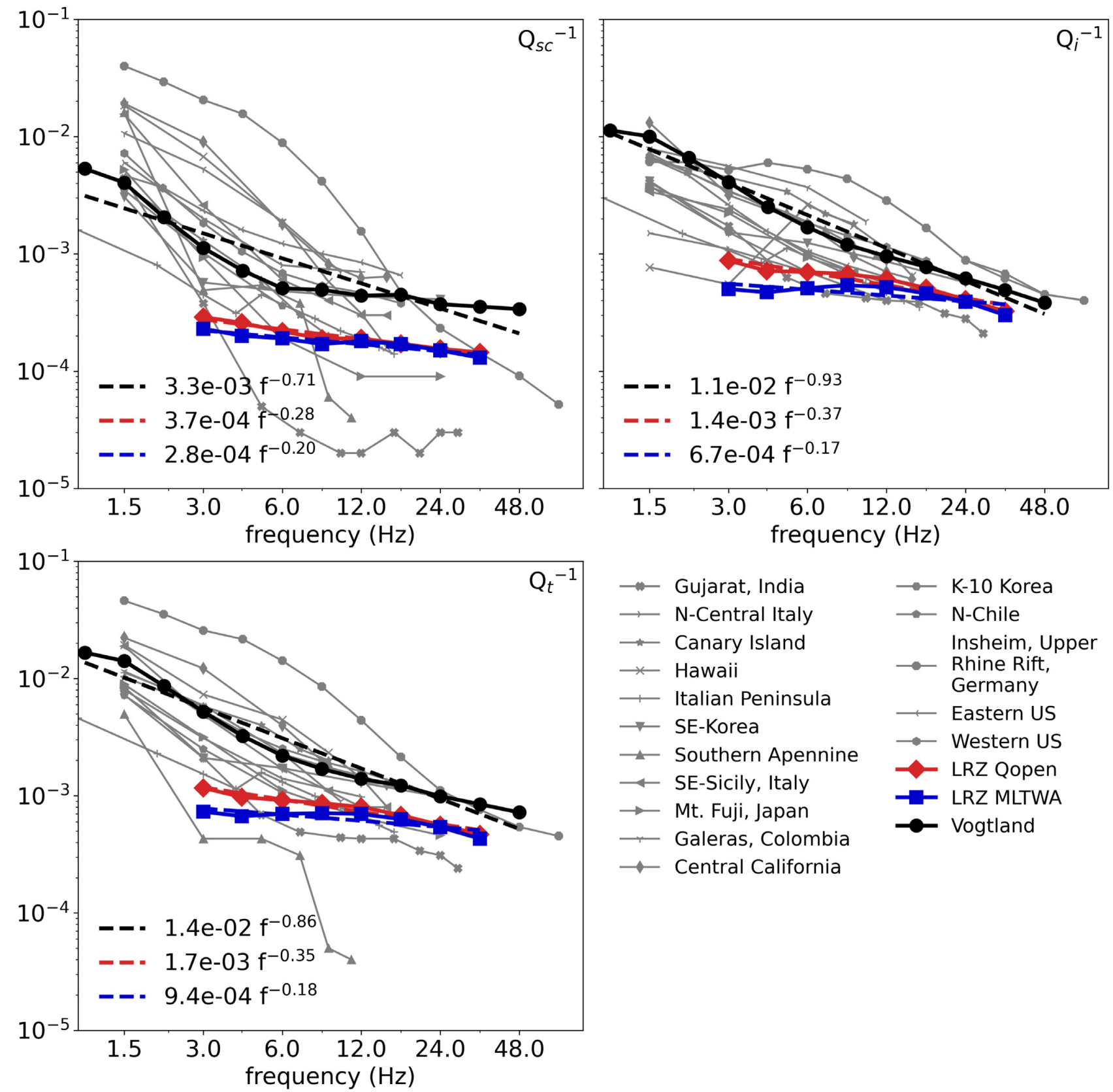

Figure 12. Qopen (red) and MLTWA (blue) results of this study and the results of Gaebler et al. (2015) of the neighbouring Vogtland region (black) and some other studies for comparison [Gujarat, India: Ugalde et al. (2007); N-Central Italy: Del Pezzo et al. (2011); Canary Island: Canas et al. (1998); Hawaii: Mayeda et al. (1992); Italian Peninsula: Bianco et al. (2005); SE-Korea: Chung (2014); Southern Apennine: Bianco et al. (2002); SE-Sicily, Italy: Giampiccolo et al. (2006); Mt. Fuji, Japan: Chung et al. (2009); Galeras, Colombia: Ugalde et al. (2010); Central California: Mayeda et al. (1992); K-10 Korea: Chung \& Asep (2013); N-Chile: Hoshiba et al. (2001); Insheim: Eulenfeld \& Wegler (2016); Eastern \& Western US: Eulenfeld \& Wegler (2017)]. The dashed lines display the fit of the power law.

\section{CONCLUSION}

Two methods were applied to determine intrinsic and the scattering attenuation of the central LRZ region in the frequency band range between 3 and $34 \mathrm{~Hz}$. The MLTWA uses the average of three consecutive time windows of the envelope to determine the attenuation values. Qopen, on the other hand, uses the entire envelope to determine the attenuation values, as far as the SNR allows. Care should be taken when selecting the window lengths in Qopen to avoid a trade-off between $Q_{i}^{-1}$ and source displacement spectra. The time window of the direct wave should include the $S$-onset and the forward scattered waves and should be in the range of 4-10 s for local studies. For the coda time window, we recommend a minimum length of $30 \mathrm{~s}$ to avoid trade-offs. The results show that both methods provide identical values within their error bars. On closer examination of the data, the Qopen method is more consistent with the power law of the frequency-dependent attenuation parameters for our data set than the MLTWA. In addition, Qopen can also be used to determine the site amplification of the stations and 
source spectra of the earthquakes, as well as the moment magnitude (Eulenfeld et al. 2021), which is not possible with the coda normalized MLTWA. The determined intrinsic as well as the scattering attenuation are lower in the central part of the LRZ than in its southern part. This correlates well with higher swarm earthquake activity and ascending fluids in the south. A 3-D inversion of attenuation parameters is required to image this in more detail.

\section{ACKNOWLEDGEMENTS}

We thank two anonymous reviewers whose comments contributed significantly to the improvement of the manuscript. We would also like to thank the operators of the networks TSN, SXNET, GR and CZ and the BGR. SeismicHandler was funded by the German Research Foundation (DFG) within the framework of SPP-1066. Data processing and plotting were performed with ObsPy (Krischer et al. 2015), NumPy (Harris et al. 2020) and Matplotlib (Hunter 2007).

\section{DATA AVAILABILITY}

The waveform data are available via https://eida.bgr.de/ and http://eida.gfz-potsdam.de. The topographical data can be found at https: //earthexplorer.usgs.gov/ (SRTM 2021). The MLTWA-Python code used in this work is available on request from the author. Qopen is available at: https://github.com/trichter/qopen (Eulenfeld 2021).

\section{REFERENCES}

Aki, K. \& Chouet, B., 1975. Origin of coda waves: source, attenuation and scattering effects, J. geophys. Res., 80, 3322-3342.

Aki, K., 1980. Attenuation of shear-waves in the lithosphere for frequencies from 0.05 to $25 \mathrm{~Hz}$, Phys. Earth Planet. Inter., 21, 50-60.

Bachura, M. \& Fischer, T., 2016. Coda attenuation analysis in the West Bohemia/Vogtland Earthquake Swarm Area, Pure appl. Geophys., 173, 425-437.

Bankwitz, P., Schneider, G., Kämpf, H. \& Bankwitz, E., 2003. Structural characteristics of epicentral areas in Central Europe: study case Cheb basin (Czech Republic), J. Geodyn., 35, 5-32.

Bethmann, F., Deichmann, N. \& Mai, P.M., 2011. Scaling relations of local magnitude versus moment magnitude for sequences of similar earthquakes in Switzerland, Bull. seism. Soc. Am., 101, 515-534.

Bianco, F., Del Pezzo, E., Castellano, M., Ibanez, J.M. \& Di Luccio, F., 2002. Separation of intrinsic and scattering seismic attenuation in the Southern Apennine zone, Italy, Geophys. J. Int., 150, 10-22.

Bianco, F., Del Pezzo, E., Malagnini, L., Di Luccio, F. \& Akinci, A., 2005. Separation of depth-dependent intrinsic and scattering seismic attenuation in the northeastern sector of the Italian Peninsula, Geophys. J. Int., 161, 130-142.

Bräuer, K., Kämpf, H. \& Strauch, G., 2009. Earthquake swarms in nonvolcanic regions: what fluids have to say, Geophys. Res. Lett., 36, L17309.

Calvet, M., Sylvander, M., Margerin, L. \& Villaseñor, A., 2013. Spatial variations of seismic attenuation and heterogeneity in the Pyrenees: Coda $\mathrm{Q}$ and peak delay time analysis, Tectonophysics, 608, 428-439.

Canas, J.A., Ugalde, A., Pujades, L.G., Carracedo, J.C., Soler, V. \& Blanco, M.J., 1998. Intrinsic and scattering seismic wave attenuation in the Canary Islands, J. geophys. Res., 103, 15037-15050.

Carcolé, E. \& Sato, H., 2010. Spatial distribution of scattering loss and intrinsic absorption of short-period $\mathrm{S}$ waves in the lithosphere of Japan on the basis of Multiple Lapse Time Window Analysis of Hi-net data, Geophys. J. Int., 180, 268-290.

Czech Regional Seismic Network, 2019. Institute of Geophysics, Academy of Sciences of the Czech Republic, International Federation of Digital Seismograph Networks, doi:10.7914/SN/CZ.

Chung, T.W., Lees, J.M., Yoshimoto, K., Fujita, E. \& Ukawa, M., 2009. Intrinsic and scattering attenuation of the Mt Fuji Region, Japan, Geophys. J. Int., 177, 1366-1382.

Chung, T.W. \& Asep, N.R., 2013. Multiple Lapse Time Window Analysis of the Korean Peninsula considering focal depth, J. Korean Soc. Earth Explor. Geophys., 16, 293-299 (in Korean).

Chung, T.W., 2014. Quantitative study of the separation of intrinsic and scattering seismic attenuation in southeastern Korea using the Monte Carlo simulation method, Disaster Adv., 7(3), 7-17.
Deichmann, N., 2006. Local magnitude, a moment revisited, Bull. seism. Soc. Am., 96, 1267-1277.

Del Pezzo, E., Bianco, F., Marzorati, S., Augliera, P., D’Alema, E. \& Massa, M., 2011. Depth-dependent intrinsic and scattering seismic attenuation in north central Italy, Geophys. J. Int., 186, 373-381.

Emoto, K., Saito, T. \& Shiomi, K., 2017. Statistical parameters of random heterogeneity estimated by analysing coda waves based on finite differnce method, Geophys. J. Int., 211, 1575-1584.

Eulenfeld, T. \& Wegler, U., 2016. Measurement of intrinsic and scattering attenuation of shear waves in two sedimentary basins and comparison to crystalline sites in Germany, Geophys. J. Int., 202, 744-757.

Eulenfeld, T. \& Wegler, U., 2017. Crustal intrinsic and scattering attenuation of high-frequency shear waves in the contiguous United States, $J$. geophys. Res., 122, 4676-4690.

Eulenfeld, T., 2021. trichter/qopen (Zenodo), doi:10.5281/zenodo.3953654.

Eulenfeld, T., Dahm, T., Heimann, S. \& Wegler, U., 2021. Fast and robust earthquake source spectra and moment magnitudes from envelope inversion, Bull. seism. Soc. Am.,, https://arxiv.org/abs/2107.11083.

Fehler, M., Hoshiba, M., Sato, H. \& Obara, K., 1992. Separation of scattering and intrinsic attenuation for the Kanto-Tokai region, Japan, using measurements of S-wave energy versus hypocentral distance, Geophys. J Int., 108, 787-800.

Fischer, T., Horálek, J., Hrubcová, P., Vavryčuk, V., Bräuer, K. \& Kämpf, H., 2014. Intra-continental earthquake swarms in West-Bohemia and Vogtland: a review, Tectonophysics, 611, 1-27.

Gaebler, P.J., Eulenfeld, T. \& Wegler, U., 2015. Seismic scattering and absorption parameters in the W-Bohemia/Vogtland region from elastic and acoustic radiative transfer theory, Geophys. J. Int., 203, 1471-1481.

Giampiccolo, E., Tuvè, T., Gresta, S. \& Patanè, D., 2006. S-waves attenuation and separation of scattering and intrinsic absorption of seismic energy in southeastern Sicily (Italy), Geophys. J. Int., 165, 211-222.

German Regional Seismic Network, 2019. Federal Institute for Geosciences and Natural Resources (BGR), doi:10.25928/MBX6-HR74.

Grünthal, G., Bankwitz, P., Bankwitz, E., Bednarek, J., Guterch, B., Schenk, V. Schenková Z. \& Zeman, A., 1985. Seismicity and geological features of the eastern part of the West European Platform, Gerlands Beiträge zur Geophys., 94, 276-289.

Hanks, T.C. \& Kanamori, H., 1979. A moment magnitude scale, J. geophys. Res., 84, 2348-2350.

Harris, C.R. et al., 2020. Array programming with NumPy, Nature, 585, 357-362.

Heimann, S. et al., 2018. Grond - a probabilisitc earthquake source inversion framework, GFZ Dat Servives, doi:10.5880/GFZ.2.1.2018.003.

Hemmann, A., Meier, T., Jentzsch, G. \& Ziegert, A., 2003. Similarity of waveforms and relative relocalisation of the earthquake swarm 1997/1998 near Werdau, J. Geodyn., 35, 191-208. 
Hunter, J.D., 2007. Matplotlib: a 2D Graphics Environment, Comput. Sci. Eng., 9, 90-95.

Hofmann, Y., Jahr, T. \& Jentzsch, G., 2003. Three-dimensional gravimetric modelling to detect the deep structure of the region Vogtland/NWBohemia, J. Geodyn., 35, 209-220.

Hoshiba, M., Rietbrock, A., Scherbaum, F., Nakahara, H. \& Haberland, C., 2001. Scattering attenuation and intrinsic absorption using uniform and depth dependent model - Application to full seismogram envelope recorded in Northern Chile, J. Seismol., 5, 157-179.

Ibs-von Seht, M., Plenefisch, T. \& Klinge, K., 2008. Earthquake swarms in continental rifts - a comparison of selected cases in America, Africa and Europe, Tectonophysics, 452, 66-77.

Krischer, L., Megies, T., Barsch, R., Beyreuther, M., Lecocq, T., Caudron, C. \& Wassermann, J., 2015. ObsPy: a bridge for seismology into scientific Python ecosystem, Comput. Sci. Discov., 8(1), 014003.

Korn, M., Funke, S. \& Wendt, S., 2008. Seismicity and seismotectonics of West Saxony, Germany - new insights from recent seismicity observed with the Saxonian seismic network, Stud. Geophys. Geod., 52, 479-492.

LfULG - Sächsisches Landesamt für Umwelt, Landwirtschaft und Geologie, 2018. Digitales geologisches und seismologisches Kartenmaterial des Freistaates Sachsen, Available at: https://www.lfulg.sachsen.de/karte n-und-daten-13433.html.

Mayeda, K., Koyanagi, S., Hoshiba, M., Aki, K. \& Zeng, Y., 1992. A comparative study of scattering, intrinsic, and coda $Q^{-1}$ for Hawaii, Long Valley, and central California between 1.5 and $15.0 \mathrm{~Hz}$, J. geophys. Res., 97, 6643-6659.

Mayor, J., Calvet, M., Margerin, L., Vanderhaeghe, O. \& Traversa, P., 2016. Crustal structure of the Alps as seen by attenuation tomography, Earth planet. Sci. Lett., 439, 71-80.

Meirova, T. \& Pinsky, V., 2014. Seismic wave attenuation in Israel region estimated from the multiple lapse time window analysis and S-wave coda decay rate, Geophys. J. Int., 197, 581-590.

Mousavi, S., Bauer, K., Korn, M. \& Hejrani, B., 2015. Seismic tomography reveals a mid-crustal intrusive body, fluid pathways and their relation to the earthquake swarms in West Bohemia/Vogtland, Geophys. J. Int., 203, 1113-1127.

Neunhöfer, H., 1998. Das Bulletin der lokalen Erdbeben im Vogtland 19621997, DGG Mitteilung, 4, 2-7 (n German).

Neunhöfer, H. \& Hemmann, A., 2005. Earthquake swarms in the Vogtland/Western Bohemia region: spatial distribution and magnitudefrequency distribution as an indication of the genesis of swarms?, $J$. Geodyn., 39, 361-385.

Paasschens, J., 1997. Solution of the time-dependent Boltzmann equation, Phys. Rev. E, 56, 1135-1141.

Pitzsch, K., 1963. Geologie von Sachsen, Dt. Verl. Wiss., Berlin, in German.
Przybilla, J., Korn, M. \& Wegler, U., 2006. Radiative transfer of elastic waves versus finite difference simulations in two-dimensional random media, $J$. geophys. Res., 111, 148-227.

Saito, T., Sato, H., Ohtake, M. \& Obara, K., 2005. Unified explanation of envelope broadening and maximum-amplitude decay of high-frequency seismograms based on the envelope simulation using the Markov approximation: forearc side of the volcanic front in northeastern Honshu, Japan, J. geophys. Res., 110, B01304, doi:10.1029/2004JB003225.

Sato, H., Fehler, M.C. \& Maeda, T., 2012. Seismic Wave Propagation and Scattering in the Heterogeneous Earth, 2nd edn., Springer, Berlin.

Sens-Schönfelder, C. \& Wegler, U., 2006. Radiative transfer theory for estimation of the seismic moment, Geophys. J. Int., 167, 1363-1372.

Sens-Schönfelder, C., Margerin, L. \& Campillo, M., 2009. Laterally heterogeneous scattering explains Lg blockage in the Pyrenees, J. geophys. Res., 114, 148-227.

Shearer, P.M. \& Earle, P.S., 2004. The global short-period wavefield modelled with a Monte Carlo seismic phonon method, Geophys. J. Int., 158, $1103-1117$.

Shito, A. et al., 2020. 3-D intrinsic and scattering seismic attenuation structures beneath Kyushu, Japan, J. geophys. Res., 125, e2019JB018742, doi:10.1029/2019JB018742.

Shuttle Radar Topography Mission (SRTM) Non-Void Filled, 2021 , doi:10.5066/F7K072R7.

Špičak, A. \& Horálek, J., 2001. Possible role of fluids in the process of earthquake swarm generation in the West Bohemia/Vogtland seismoactive region, Tectonophysics, 336, 151-161.

Stammler, K., 1993. SeismicHandler: programmable multichannel data handler for interactive and automatic processing of seismological analyses, Comput. Geosci., 19, 135-140.

Saxon Seismic Network, 2019. University of Leipzig, International Federation of Digital Seismograph Networks, doi:10.7914/SN/SX.

Thüringer Seismologisches Netz, 2019. Institut für Geowissenschaften, Friedrich-Schiller-Universität Jena, International Federation of Digital Seismograph Networks, doi:10.7914/SN/TH.

Ugalde, A., Tripathi, J.N., Hoshiba, M. \& Rastogi, B.K., 2007. Intrinsic and scattering attenuation in western India from aftershocks of 26 January, 2001 Kachchh earthquake, Tectonophysics, 429, $111-123$.

Ugalde, A., Carcolé, E. \& Cargas, C.A., 2010. S-wave attenuation characteristics in the Galeras volcanic complex (south western Colombia), Phys. Earth planet. Inter., 181, 73-81.

Weise, S., Bräuer, K., Kämpf, H., Strauch, G. \& Koch, U., 2001. Transport of mantle volatiles through the crust traced by seismically released fluids: a natural experiment in the earthquake swarm area Vogtland/NW-Bohemia, Central Europe, Tectonophysics, 336, 137-150. 